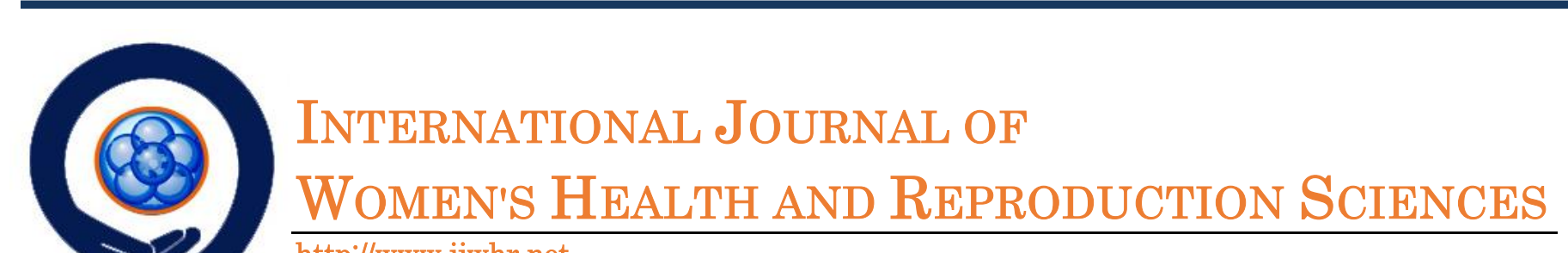

http://www.ijwhr.net

doi: 10.15296/ijwhr.2014.20

\title{
Preventive Analgesia with Intravenous Paracetamol for Post-cesarean section Pain Control
}

\author{
Simin Atashkhoyi ${ }^{1 *}$, Sousan Rasouli ${ }^{1}$, Zahra Fardiazar ${ }^{2}$, Morteza Ghojazadeh ${ }^{3}$, \\ Pouya Hatami Marandi 4
}

\section{Article History:}

Received 10 December 2013

Accepted 2 February 2014

Revised 15 January 2014

Available online 4 February 2014

\section{Keywords: \\ Cesarean section \\ Paracetamol \\ Postoperative pain \\ Preventive analgesia}

\section{Corresponding Author:}

Simin Atashkhoyi, Associate Professor of Anesthesiology, Women's Reproductive Health Research Center, Tabriz University of Medical Sciences, Tabriz, Iran. Tel: +989141148861

Email: satashkhoyi@gmail.com

\begin{abstract}
Objectives: Effective pain therapy after cesarean section is essential for parturient comfort and to allow early ambulation to facilitate care of her infant. This study evaluated the analgesic effect of preventive 1gr intravenous paracetamol on postoperative pain and analgesic consumption during the 24 hours after cesarean section.

Materials and Methods: One-hundred American Society of Anesthesiologists (ASA) I or II status parturient scheduled for elective cesarean section under spinal anesthesia. Patients received $1 \mathrm{gr}$ iv paracetamol into $100 \mathrm{ml}$ normal saline (study group; $\mathrm{n}=50$ ) or normal saline alone (placebo group; $\mathrm{n}=50$ ) 20 minutes before the end of operation.

Results: Pain scores were lower in the study group in the Post anesthesia care unit $(\mathrm{PACU})(\mathrm{p}<0.001)$ and up to $4 \mathrm{~h}$ after operation $(p<0.001)$. Cumulative analgesic consumption was lower in the study group $(\mathrm{p}<0.001)$.

Conclusion: Preventive administration of $1 \mathrm{gr}$ iv paracetamol reduces the intensity of pain in the PACU and until $4 \mathrm{~h}$ after operation and analgesic consumption following cesarean section.
\end{abstract}

1- Associate Professor of Anesthesiology, Women's Reproductive Health Research Center, Tabriz University of Medical Sciences, Tabriz, Iran.

2- Professor of Obstetrics \& Gynecology, Women's Reproductive Health Research Center, Tabriz University of Medical Sciences, Tabriz, Iran.

3- Associate Professor of Physiology, Women's Reproductive Health Research Center, Tabriz University of Medical Sciences, Tabriz, Iran.

4- Medicine Student, Tabriz University of Medical Sciences, Tabriz, Iran. 


\section{Introduction:}

Cesarean section (C.S) is the one of the most common surgical procedure in women. Patients undergoing C.S may experience significant postoperative pain (1). Pain after cesarean delivery may impair the bond of affection and early interaction between mother and infant, the mother's ability to care and feed for her child, early ambulation and discharge (2). Chronic pain also is a complication of cesarean delivery. Approximately $12.3 \%$ of patients experience pain scores enough to affect infant care up to 6 months after delivery (3).

Various approaches have recommended for the treatment of pain after C.S. Systemic and neuraxial opioids is commonly used modality for post-cesarean delivery pain relief $(4,5)$. However, opioids have dosedependent potential for serious adverse reactions including nausea, vomiting, constipation, pruritus, urinary retention, respiratory depression, sedation, and importantly risks for neonate infant from the breast milk exposure to opioids $(4,6)$.

Preventive analgesia includes any intraoperative analgesic agents able to control pain-induced sensitization of the central nervous system (CNS), hence to decrease both the development and the persistence pain (7).

Paracetamol (intravenous acetaminophen) is a non-opioid analgesic that is devoid of risks related to opioids $(8,9)$. The postoperative use of paracetamol has been shown to decrease acute pain after various surgical procedures (10). Although there is few data on the analgesic affection of a preoperative (pre-emptive) administration of paracetamol $(11,12)$, there are no data on the efficacy of the preventive (intraoperative or the end of surgery) administration of paracetamol on the postoperative pain.

The aim of this study was to evaluate the analgesic effect of administration of $1 \mathrm{gr}$ intravenous paracetamol at the end of surgery (preventive analgesia) on postcesarean delivery pain parameters.

\section{Material \& Methods:}

After the medical ethics committee approval and written consent obtained from participants, 100 pregnant women were enrolled in this prospective, randomized, and double blind clinical trial. The inclusion criteria were physical status American society of anesthesiologists (ASA) I-II, aged 18-39 years, and term pregnancy undergoing elective C.S with spinal anesthesia. Exclusion criteria included preeclampsia, cardiovascular, respiratory, hepatic or renal problems, known allergy to any study medications, chronic pain syndrome, daily analgesic therapy, contraindication for spinal puncture, and psychological disorders.

No patients received premedication. Patients were fasted for 6 hours. In the operating room, routine standard monitoring with non-invasive arterial pressure (NIBP) electrocardiography (ECG) and pulse-oximetry was established. Baseline measurements were performed 5 minutes before spinal anesthesia. A canola was introduced into a peripheral vein. Each patient was preloaded with $10-12 \mathrm{ml} / \mathrm{kg}$ of ringer lactate solution. With the patient in the sitting position, lumbar puncture was performed at the L2-3 or L3-4 interspaces with $1.5 \mathrm{ml}$ of $5 \%$ hyperbaric lidocaine (Lidocaine spinal 5\% Heavy; Orion corporation, Espoo, Finland) and $15 \mu \mathrm{g}$ fentanyl in $1.5 \mathrm{ml}$ via a 25-Gauge Quincke spinal needle. Total volume of subarachnoid solution was $3 \mathrm{ml}$. Patients were positioned supine on the operating table and were kept in 150 left lateral tilt until delivery of the neonate. Sensory block to T5 dermatome was considered adequate for surgery.

After delivery and uterus repairmen, parturient were assigned to receive one of two study solutions using a block randomization schedule: study group $(\mathrm{n}=50)$ received $1 \mathrm{~g}$ paracetamol (Apotel $1000 \mathrm{mg}$, iv UNI-PHARMA.S.A. LOT NO: 1111) into $100 \mathrm{ml}$ normal saline over 15 minutes and placebo group $(n=50)$ received $100 \mathrm{ml}$ normal saline alone, 20 minutes before the end of procedure.

Changes in maternal hemodynamics (MAP and HR) throughout anesthesia and side effects were recorded. In the post-anesthesia care unit (PACU) and during 24 hours postoperatively, the pain scale was obtained 
using by visual analogue scale (VAS; 0 to 10). Time to first analgesic rescue, time of ambulation, and side effects (nausea, vomiting, sedation, and hemodynamic changes) during $24 \mathrm{~h}$ postoperatively were recorded.

Operations were performed by any of three obstetric surgeons and two anesthesiologists managed anesthesia. An anesthesiologist who was not involved in the study solutions performed the collection of the data. During $24 \mathrm{~h}$ post-operatively, iv paracetamol $1000 \mathrm{mg}$ was given for $\mathrm{VAS} \geq 4$ as needed, and sodium diclofenac suppository $100 \mathrm{mg}$ for VAS $<4$. For break through pain, patients were treated with iv meperidine $0.5 \mathrm{mg} / \mathrm{kg}$.

The sample size was based on preliminary data from previous study 12 . We determined that an effective sample- size of $n=100$ (50 per group) would be require for the current study to provide statistical power (twotailed, $\alpha=0.05$ ) of $80 \%$ to detect a mean difference between groups.

Data were presented as means (SD), median (range), and counts (number). Means were analyzed using student's $t$ test, medians using Mann-whitney U-test and counts using Fisher,s exact and $\mathrm{x} 2$ tests. All analyses were performed using the SPSS statistical software, version 15.00 (SPSS Inc., ChicagoIL, USA). The level of statistical significance for all tests was $\mathrm{p}<0.05$.

\section{Results:}

There are no significant differences between the groups concerning age, weight, height, duration of surgery and anesthesia, indication for C.S, gravidity, and iv fluid (table1). There were no significant differences regarding to peri-operative hemodynamic parameters between two groups (fig1).

The pain scores were significantly lower for patients in the study group in the PACU $(\mathrm{p}<$ 0.0001 ), and up to 4 hours postoperatively $(p<0.001)$ than those in the placebo group, but not at $8,12,16,20$, and 24 hours after surgery (fig 2). The number of patients without any postoperative pain during first $24 \mathrm{~h}$ in study and placebo groups were 5 and 0 respectively $(\mathrm{P}=0.09 ;$ table 2$)$. Table 2 shows also that the time to first analgesic request were significantly longer in the study group ( $265.26 \pm 5.68$ vs $21.16 \pm 17.62$; $\mathrm{p}<0.0001)$.

Cumulative postoperative analgesic consumption (paracetamol and meperidine) was lower in the study group than the placebo group $(\mathrm{p}<0.001$ and $\mathrm{p}=0.02$; respectively)

There was no significant differences in terms of PONV between two groups ( $12 \%$ vs $4 \%$; $\mathrm{p}=0.16$ ). Other postoperative side effects also were absent in both groups.

\section{Discussion:}

The results of this study demonstrate that preventive of iv $1 \mathrm{gr}$ paracetamol administration at the end of procedure reduced pain scores in the PACU and up to 4 hours postoperatively and analgesic medications consumption after C.S.

A few studies have been investigated paracetamol preoperatively. Moon Ye et al (12) evaluated the preoperative intravenous acetaminophen in patients undergoing abdominal hysterectomy and reported premedication with paracetamol reduced opioid consumption and opioid-related side effects in patients. Mound E et al (13) also in a systematic review concluded that when paracetamol, NSAIDs, and COX- 2 inhibitors are compared with each other, the differences in opioid consumption were small.

In present study, we compared the efficacy of preventive administration of paracetamol with patients who received placebo. Bilgin Het al (14) suggested that single-dose preventive ketamine, provided better analgesia compared with when ketamine was administrated preoperatively in patients undergoing gynecologic laparotomy. In previous our study we reported also preventive epidural analgesia with bupivacaine and fentanyl associated with the lower pain scores and opioid requirements postoperatively in patients undergoing major gynecologic surgery (15). A dose of 1gr paracetamol given before the end of surgery, the same dose of paracetamol given in other studies $(16,17)$. Although Juhl Glet al (18). reported 2g of paracetamol preoperatively, was superior over the recommended dose of $1 \mathrm{gr}$ in terms 
of magnitude and duration of analgesic effect for postoperative pain following third molar surgery.

Our results were related to pharmacological action of the drug. Acetaminophen inhibits cyclooxygenase activity (COX-3) in central nervous system (CNS). In addition, paracetamol is a weak COX-1 and COX-2 inhibitor (anti-inflammatory effect) $(8,13$, 19).

In this study, measurements of blood pressure and heart rate in patients throughout the study period suggest that paracetamol does not have cardiovascular effects. However, paracetamol at higher doses may exhibit stronger non-selective COX inhibitor activity and thereby reducing blood pressure (20).

Incidence of adverse effects did not differ significantly between two groups. Nausea occurred in $4 \%$ of patients in placebo group. This effect may be due to the larger doses of meperidine use in placebo group. Cok OY et al (21) showed that intraoperative paracetamol decreases the incidence of PONV during the first $24 \mathrm{~h}$ in children after strabismus surgery. There are limitations to the present study. First, patients were not follow-up regard to chronic pain. Second, we did not have preoperative analgesic injection (pre-emptive) group. The timing of pre-emptive administration of analgesic is importance.

\section{Conclusion :}

Single dose of intravenous 1gr paracetamol administered the end of operation, provides effective preventive analgesia after cesarean section.

\section{Conflicts of interest:}

Authors declare that there is no any conflict of interest.

\section{Acknowledgments:}

This research was supported by Women's Reproductive Health Research Center, Tabriz University of Medical Sciences, Tabriz, Iran. The code of this research protocol was 91114.

Figure 1. Maternal heart rate (A) and mean arterial pressure (B) changes during operation.

${ }^{*} \mathrm{p}>0.05$ at all times.

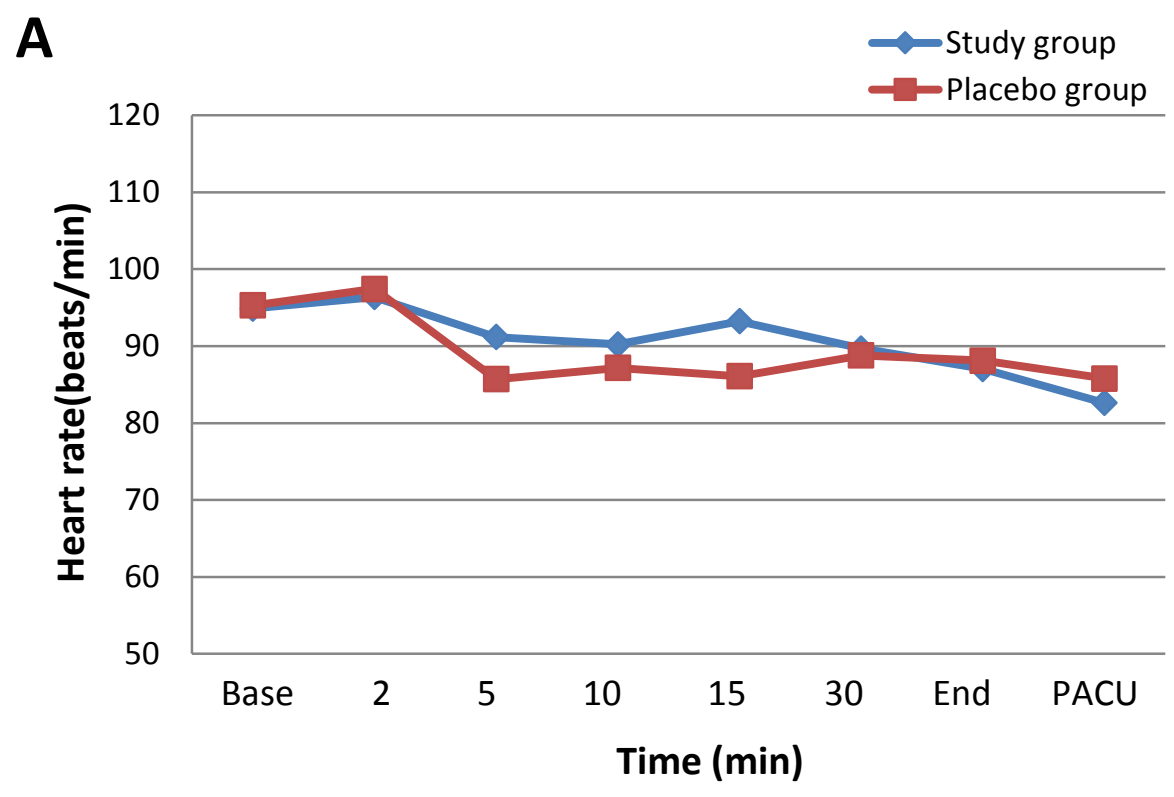




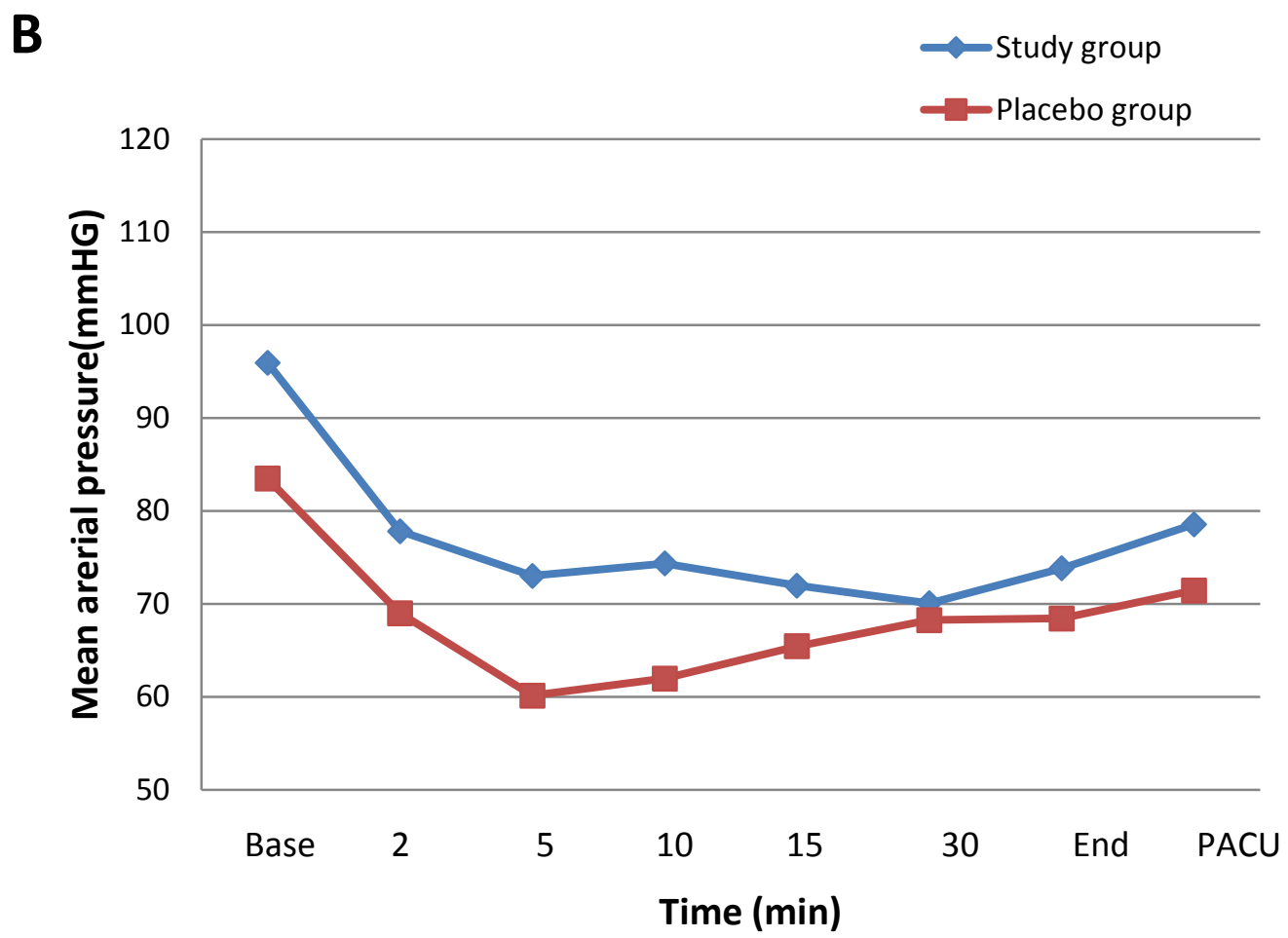

Table1. Patient's characteristics and intra-operative variables in two groups.

\begin{tabular}{|c|c|c|c|}
\hline & $\begin{array}{l}\text { Study group } \\
\quad(n=50)\end{array}$ & $\begin{array}{l}\text { Placebo group } \\
\qquad(\mathrm{n}=50)\end{array}$ & $\mathrm{p}$ \\
\hline Age (yr) & $29.84 \pm 5.19$ & $28.70 \pm 5.90$ & 0.25 \\
\hline Weight (kg) & $79.80 \pm 13.47$ & $76.67 \pm 10.45$ & 0.29 \\
\hline $\operatorname{Height}(\mathrm{cm})$ & $159.36 \pm 5.07$ & $158.84 \pm 5.64$ & 0.16 \\
\hline Cause of cesarean section (\%) & & & 0.22 \\
\hline -Breech & $4(8)$ & $6(14)$ & \\
\hline$-\mathrm{CPD}$ & $19(34)$ & $15(26)$ & \\
\hline -Repeated & $24(52)$ & $27(58)$ & \\
\hline -Tween & $3(6)$ & $2(4)$ & \\
\hline Block height at skin incision & T4(T3-T6) & T3(T2-T5) & 0.16 \\
\hline Gravidity $(1 / 2 / 3$ or more $)(\mathrm{N})$ & $26 / 20 / 4$ & $30 / 15 / 5$ & 0.59 \\
\hline Duration of operation (min) & $58.38 \pm 6.88$ & $58.44 \pm 6.89$ & 0.96 \\
\hline Duration of sensory block (min) & $74.34 \pm 5.03$ & $75.64 \pm 5.34$ & 0.21 \\
\hline Total iv fluid during anesthesia(ml) & $2270 \pm 265.92$ & $2204 \pm 195.05$ & 0.16 \\
\hline
\end{tabular}

Number(\%) and mean (SD) 
Table2. Postoperative variables in two groups.

\begin{tabular}{lccc}
\hline & $\begin{array}{c}\text { Study group } \\
(\mathrm{n}=50)\end{array}$ & $\begin{array}{c}\text { placebo group } \\
(\mathrm{n}=50)\end{array}$ & $\mathrm{P}$ \\
\hline Patients without any postoperative pain $(\%$ & $5(10)$ & $0(0)$ & 0.09 \\
Time to first analgesic request(min) & $265.26 \pm 5.68$ & $21.16 \pm 17.62$ & $<0.0001$ \\
Time to ambulation (h) & $5.09 \pm 0.75$ & $5.93 \pm 0.64$ & $<0.001$ \\
Paracetamol consumption postoperatively(gr) & $0.42 \pm 0.49$ & $1540.0 \pm 676.0$ & $<0.001$ \\
Diclofenac suppository consumption(mg) & $62.00 \pm 53.03$ & $90.0 \pm 81.44$ & 0.09 \\
Meperidine consumption (mg) & $0.00 \pm 0.00$ & $2.0 \pm 6.06$ & 0.02 \\
Incidence of PONV (\%) & $6(12)$ & $2(4)$ & 0.16 \\
\hline
\end{tabular}

Number (\%) and mean (SD)

\section{References:}

1. Bilgen S, Koner O, Ture H, Menda F, Ficicioglu C, Aykac B. Effect of three doses of ketamine prior to general anesthesia on postoperative pain following cesarean delivery: a prospective randomized study. Minerva Anesthesiol. 2011; 7(4):1-8.

2. Gadsden J, Hart S, Santos AC.Post-Cesarean Delivery Analgesia.AnesthAnalg. 2005; 101(5 Supp):S62-9.

3. Moore A, Costello J, Wieczorek P, Shah V, Taddio A, Carvalho JC. Gabapentin Improves Post-cesarean Delivery PainManagement: A Randomized, Placebo-Controlled Trial. Anesth Analg. 2011; 112(1):167-73.

4. Belavy D, Cowlishaw PJ, Howes M, Phillips F. Ultrasound-guided transverses abdominis plane block for analgesia after Cesarean delivery. Br J Anesth. 2009; 103(5):726-30.

5. Kanazi GE, Aouad MT, Abdallah FW, Khatib MI, Adham MBF, Harfoush DW, et al. The analgesic efficacy of subarachnoid morphine in comparison with ultrasound-guided transverses abdominis plane block after cesarean delivery: a randomized controlled trial. Anesth Analg. 2010; 111(2):475-81.

6. Dieterich M, Muller-Jordan K, Stubert J, Kundt G, Wagner K, Gerber B. Pain management after cesarean: a randomized controlled trial of oxycodone versus intravenous piritramide. Arch Gynecol Obstet. 2012; 286(4):859-65.

7. Shen XF, Wang F, Xu S, Ma L, Liu Y, Feng S, et al. Comparison of the analgesic efficacy of preemptive and preventive tramadol after lumpectomy. Pharmacol Report. 2008; 60(3):41521.

8. Uysal HY, Takmaz SA, Yaman F, Baltaci B, Başar H.The efficacy of intravenous paracetamol versus tramadol for postoperative analgesia after adenotonsillectomy in children.J Clin Anesth. 2011; 23(1): 53-7.

9. Coulthard P, Hill CM, Frame JW, Barry H, Ridge BD, Bacon TH. Pain control with paracetamol from a sustained release formulation and a standard release formulation after third molar surgery: a randomised controlled trial.Br Dent J. 2001;191(6):319-26. 
10. Wininger SJ, Miller H, Minkowitz HS, Royal MA, Ang RY, Breitmeyer JB, et al.A Randomized, Double-Blind, Placebo-Controlled, Multicenter, Repeat-Dose Study of Two Intravenous Acetaminophen Dosing Regimens for the Treatment of Pain after Abdominal Laparoscopic Surgery.ClinTher. 2010; 32(14):2348-69.

11. Munishankar B, Fettes P, Moore C, McLeod GA. A double-blind randomized controlled trial of paracetamol, diclofenac or the combination for pain relief after caesarean section. Int $\mathrm{J}$ ObstetAnesth. 2008; 17(1):9-14.

12. Moon YE, Lee YK, Lee J, Moon DE.The effects of preoperative intravenous acetaminophen in patients undergoing abdominal hysterectomy.Arch Gynecol Obstet. 2011; 284(6):1455-60.

13. Maund E, McDaid C, Rice S, Wright K, Jenkins B, Woolacott N. Paracetamol and selective and non-selective non-steroidal anti-inflammatory drugs for the reduction in morphine-related side-effects after major surgery: a systematic review. Br J Anaesth. 2011; 106 (3):292-97.

14. Bilgin H, Ozcan B, Bilgin T, Kerimoglu B, Uckunkaya N, Toker A, et al. The influence of timing of systemic ketamine administration on postoperative morphine consumption.J ClinAnesth. 2005; 17(8):592-7.

15. Atashkhoyi S, JafariShobeiri M, AzariKalejahiA, HatamiMarandi P. Comparison of Preemptive with Preventive Epidural Analgesia in the Patients Undergoing Major Gynecologic Surgery. Afr J Pharma Pharmacol. 2013; 7(6):245-9.

16. Mowafi HA, AbouElmakarim E, Ismail S, Al-Mahdy M, El-Saflan AE, Elsaid AS. Intravenous Lornoxicam Is More Effective than Paracetamol as a Supplemental Analgesic After Lower Abdominal Surgery: A Randomized Controlled Trial. World J Surg. 2012; 36(9):2039-44.

17. Arslan M, Cicek R, Celep B, UstunKalender H. Comparison of the analgesic effects of intravenous paracetamol and lornoxicam in postoperative pain following thyroidectomies. Agri. 2011; 23(4):160-6.

18. Juhl GI, Norholt SE, Tonnesen E, Hiesse-Provost O, Jensen TS. Analgesic efficacy and safety of intravenous paracetamol (acetaminophen) administered as a $2 \mathrm{~g}$ starting dose following third molar surgery. Eur J Pain. 2006; 10(4):371-7.

19. Kesimci E, Gumus T, IzdesSeval, Şen P, Kanbak O. Comparison of efficacy of dexketoprofen versus paracetamol on postoperative pain and morphine consumption in laminectomy patients. Agri. 2011; 23(4):153-9.

20. Den Hertog HM, Van der Worp HB, Van Gemert HMA, Van Gijn J, Koudstaal PJ, Dippel DWJ. Effects of high-dose paracetamol on blood pressure in acute stroke. Acta Neurol Scand. 2012: 125(4):265-71.

21. Cok OY, Eker HE, Pelit A, Canturk S, Akin S, Aribogan A, et al. The effect of paracetamol on postoperative nausea and vomiting during the first $24 \mathrm{~h}$ after strabismus surgery: a prospective, randomized, double-blind study. Eur J Anesthesiol. 2011; 28(12):836-41. 